\title{
EU, TU, AS NANOTECNOLOGIAS E O OUTRO: QUAL A CONTRIBUIÇÃO DO DIÁLOGO ENTRE BUBER E OST PARA O HOMEM?
}

Daniela Regina Pellin * Fábio da Silva Veiga **

\section{RESUMO}

Eu se divorciou de Tu e relacionou-se promíscua e intensamente com Isso. Um descompasso entre o desenvolvimento humano e o econômico é promovido pelo excesso de técnica. As nanotecnologias são ferramentas mágicas de acumulação. As sociedades padecem dos riscos. O homem encontra-se escravizado pela técnica. A retomada da relação transcendental entre Eu-Tu; o abandono de Isso e o (re) visitar do imaginário social podem servir de parâmetros para o sistema dialógico entre a práxis e o $\log o s$, e, com isso, a gestão eficiente dos riscos nanotecnológicos com boas prospecções sociais futuras e, o cumprimento do escopo Constitucional do art. 170.

PALAVRAS-CHAVES: Nanotecnologias. Riscos. Transcendentalidade. Imaginário Social. Gestão. Efetividade.

\section{I, YOU, THE NANOTECHNOLOGIES AND THE OTHER: WHAT IS THE CONTRIBUTION FROM THE DIALOGUE BETWEEN BUBER AND OST TO THE MAN?}

\begin{abstract}
I divorced You and related to promiscuous and intensely with It. A mismatch between human development and economic is promoted by excess technique. Nanotechnologies are magical accumulation tools. Societies suffer risks. The man has been enslaving by technology. The resumption of the transcendental relationship between I-You (Martin Buber); the abandonment of It and the (re) visit the social imaginary (François Ost) can serve as parameters for the dialogic system between praxis and logos, and thus, the efficient management of nanotechnological risks with good future social surveys and compliance with the Constitutional scope of article 170.
\end{abstract}

Keywords: Nanotechnologies. Risks. Transcendentality. Social Imaginary. Management. Constitutional effectiveness

\footnotetext{
* Doutoranda em Direito Público na UNISINOS/RS. Bolsista UNISINOS/CAPS/PROEX. Mestre em Direito da Sociedade da informação. Especialista em Direito Empresarial. Professora. Pesquisadora em Direito, Sociedade e Novas Tecnologias. Advogada. Membro do Grupo de Pesquisa JUSNANO/CNPq. Email: daniela.pellin@ terra.com.br

* * Doutor em Direito Empresarial pela Universidade de Vigo. Professor de Direito Empresarial no Máster en Abogacía da Universidad Europea de Madrid. Pesquisador do Programa de Doutorado em Direito da Universidad de Alcalá, Madrid, com bolsa DPE/CAPES. Presidente do IBEROJUR - Instituto Iberoamericano de Estudos Jurídicos. E-mail: fabio.da@uah.es
} 


\section{Introdução}

As nanotecnologias representam o ápice do desenvolvimento da razão técnica no homem, tomando como compreensão o conceito de Umberto Galimberti (2014), para quem "a técnica não é uma entidade, é uma racionalidade de visão generalizada”.

Entretanto, se tais confirmam o último estágio de evolução da razão humana, não é menos importante verificar que subtraiu do Homem, a capacidade de enxergar-se sem a técnica, a qual ocupou todo o espaço de reflexão e realização individual ou coletiva: a razão instrumental. Por isso, Galimberti (2014) diz que os efeitos disso são a supervalorização do que é útil e necessário e a incompreensão do que é bom, belo, verdadeiro; o que é santo e o que é justo.

Essa separação histórica entre a razão prática e a razão transcendental é parte da inquietação do presente ensaio e, por isso, propõe uma reunião conjunta de ambas para alavancar o campo das reflexões no que concerne às incertezas trazidas pelas nanotecnologias. O fruto dessa audiência intelectual será a retomada desse diálogo em homenagem aos velhos tempos; pois, ao lado dos avanços que as nanotecnologias promovem, os riscos ao ecossistema natural e artificial, também, se apresentam. Dessa nova-velha união espera-se a geração de resultados filosóficos como fatores de decisão tecnológica, na prática, a exemplo da ponderação do reto conselho, como disse Ésquilo a Prometeu.

Para o enfrentamento dessa problemática e o esquecimento do Homem em sua plenitude como fim do desenvolvimento, adotar-se-á inflexões e reflexões filosóficas de Martin Buber, ao lado de observações jurídicas, sociais e históricas de François Ost. Ambos almejam com suas obras o mesmo fim: colocar o Homem como fim de toda decisão tecnológica. O diálogo entre ambos pode contribuir, com originalidade, ao restabelecimento desse novo-velho enlace e possibilitar a reorganização da relação entre sujeito e objeto e, com isso, mitigar e, até mesmo, repensar os riscos na tomada de decisão exploratória.

Nesse contexto, o objetivo específico da pesquisa é restabelecer a posição do homem em relação a sua razão técnica e demonstrar que ainda há tempo de exercitar a habilidade para questionar os meios e os fins, bem como, entrar em contato com suas raízes tradicionais instituídas pelos antepassados. E, como objetivo geral, enfrentar o elo perdido com a transcendentalidade humana. 
Certamente que, delimitados os contornos dessa triangulação entre Eu, Tu e Isso ${ }^{1}$ e a confirmação do imaginário social, conformador das tradições como pedra estrutural das sociedades, a hipótese de que falta à razão técnica a parte transcendental do homem, poderá ser confirmada como fator de decisão sobre o desenvolvimento nanotecnológico e colocar o Homem diante do Outro $^{2}$, para uma conformação social adequada diante da práxis.

Para a realização da empreitada, será utilizada a perspectiva fenomenológica e filosófica na abordagem, bem como a coleta e análise de dados, e a revisão bibliográfica.

\section{Contextualização acerca da exploração e do desenvolvimento nanotecnológico}

Desde o advento da queda do Muro de Berlim, 1989, o capitalismo não encontrou mais barreiras substanciais ao seu avanço. Isto significa dizer que empresas transnacionais, multinacionais, Estados e Governos passaram a explorar outros territórios, interagir e relacionar-se através da macroeconomia, favorecendo as relações comerciais transfronteiriças. Foram criados os Organismos Internacionais para interferir diretamente nessas relações, nos Estados, nas culturas, na exploração econômica, no tratamento das gentes, nas soberanias.

Não bastasse, a partir de 1990, os avanços tecnológicos desenvolvidos pelos países ricos, os chamados do "Norte", iniciaram sua escalada triunfal para o topo da globalização econômica, achatando espaços territoriais e proporcionando transações econômicas simultâneas.

Tudo isso foi feito sob a pecha de levar o desenvolvimento aos países pobres e colonizados tardiamente e, nesse avanço, favorecer, rapidamente, a emancipação de tais países à condição de ricos e desenvolvidos, social, econômica e politicamente. Mas, também, é sabido que por detrás das boas intenções, estava a expansão mercadológica dos países desenvolvidos e o escoamento dos excedentes; o que significa dizer, exploração dos mercados em desenvolvimento, a exemplo dos países pobres do "Sul".

Nessa relação, surgiram novas identidades geopolíticas e econômicas: países desenvolvidos passaram a ser mais ricos, desenvolvidos e hegemônicos; países pobres, explorados e tardios, passaram a ser identificados como em desenvolvimento e ameaçados, havendo aumento significativo da pobreza, da marginalidade e da depredação dos ecossistemas.

\footnotetext{
${ }^{1}$ Para a presente pesquisa "Eu" representa o Homem em sua plenitude existencial: corpo, alma e espírito; "Tu", o Ser Superior da Criação e, "Isso", a técnica, representada pelas Nanotecnologias.

${ }^{2}$ Para a presente pesquisa "Outro" representa o outro Homem semelhante, em seu aspecto individual ou coletivo. CONPEDI LAW REVIEW | Braga - Portugal | v. 3 | n. 2 | p. 480 - 502 | JUL/DEZ. 2017
} 
Bauman (2015) relata números consideráveis a respeito do aumento do abismo mundial entre ricos e pobres a partir de um salto entre 2007 e 2010, cuja renda ficou concentrada entre Estados Unidos, Inglaterra e Qatar, informando que nos últimos 25 anos, inclusive, após a crise econômica de 2007, o aumento foi vertiginoso, de 400 para 1.120 trilhionários americanos, com o acúmulo de 4,5 trilhões de dólares em 2010, em suas mãos.

Arendt (2008) vislumbrou o abismo que a globalização promoveria; que a genialidade de Rosa Luxemburgo e seu desprendimento de Karl Marx residiu na visão clara de que o processo de crescimento não se tratava de leis inatas que regulavam o capitalismo identificado por Marx, mas sim, da existência de setores (países) pré-capitalistas que deveriam ser capturados pelo sistema capitalista e, portanto, o seu avanço na acumulação dependia do maior alcance territorial possível para manter-lhe em movimento, cujo colapso adviria, exatamente, quando o alcance global se deparasse com o seu esgotamento.

Interessante notar nesse cenário, que o Brasil é um caso típico. Desde 1988 promulgação da Constituição Federal Neoliberal Democrática vem em uma exponencial expectativa de crescimento econômico, fortalecimento social e institucional: abriu suas fronteiras para as empresas multi e transnacionais; ocupou posição de destaque em reuniões internacionais; assinou o Livro Verde da Sociedade da Informação em 2000; elaborou a legislação consumerista em 1990; o Código Civil em 2002; assinou pactos e tratados internacionais de investimentos no território; assumiu agendas de diminuição de pobreza e elevação de classes econômicas que garantissem o consumo dos produtos internalizados concedendo benefícios sociais para tal desiderato; adentrou na corrida para o desenvolvimento tecnológico. Mas, com tudo isso, a administração interna do país, deixou a desejar, pois, encontra-se a bancarrota em nível de infraestrutura, educação e saúde.

O desenvolvimento científico e tecnológico é um dos aspectos desse cenário; vem sendo encarado como a panaceia do século presente e futuro. Os avanços experimentados têm a pecha de servir ao homem de tal forma que possa contribuir com melhoria na saúde, longevidade, capacidade cognitiva, afetiva, social e cultural; dos benefícios industriais, tecnológicos e ambientais. Alerta Caubet (2013) para o fato de que todo desenvolvimento não detém atenção a eventuais malefícios, pois, não é desse sistema a preocupação.

A nanotecnologia vem sendo desenvolvida nesse contexto e ocupa posição de destaque nos investimentos públicos e privados para alimentar essa corrida desenvolvimentista. E não é só. Dada sua miniaturização ínfima e seu poder de alterar o 
estado de átomos e moléculas e tudo o que se produz, está sendo aplicada em todos os setores do desenvolvimento.

No Brasil, a Agência de Vigilância Sanitária (ANVISA), divulgou o "Diagnóstico Institucional de Nanotecnologia", em 25 de março de 2014. Mostrou que, muito embora, sendo acanhadamente desenvolvida desde 1970, foi a partir de 2005, que as nanotecnologias passaram a ser adotadas como oportunidade de alavancar mercados, cuja perspectiva até 2020, é a de estar no topo da economia de mercado massivo, como valor agregado, que é de sua natureza.

Relatou que o número de produtos manufaturados com base em nanotecnologia, também, avolumou-se: em 2005, eram entre 0 (zero) a 200; já, em 2011, já remontavam a 1600. Fato que chama a atenção é o documento mostrar que, em um levantamento realizado pela própria Agência, em convênio com o Comitê Interministerial para Nanotecnologia (CIN), em 2014, dos 637 produtos manufaturados a partir da nanotecnologia, 599 eram da área cosmética, correspondendo a $94 \%$ da produção total, o que significa, produtos manufaturados para o mercado de consumo massivo.

Alertou para a percepção dos infortúnios aos humanos em se tratando da interação entre células humanas e nanopartículas capazes de afetar o sistema gastrointestinal, cérebro, pulmões, sistema circulatório e linfático, coração, doenças autoimunes, dermatites, urticárias e vasculites, a depender da forma de ingestão ou contato com uma nanopartícula ou nanomaterial.

Engelmann e Willig, entretanto, veem o assunto dos riscos como um atributo inerente às estratégias econômicas que desprezam "[...] como efeitos negativos ao ser humano e ao seu meio ambiente, associados à inovação tecnocientífica são uma realidade presente e ameaçam a manutenção da humanidade e do seu ecossistema”. (2016, p. 127)

Mesmo assim, nesse cenário de imprevisão total, contrariando as tendências globais, ao concluir a Agenda Regulatória - Ciclo Quadrienal 2013-2016 - para o biênio 2015/2016, a ANVISA (2015) determinou o arquivamento por não se tratar de prioridade. O "Tema 74" que tratou de regulação da nanotecnologia relacionada a produtos e processos sujeitos à vigilância sanitária teve como título: "conjunto de requisitos para avaliação e controle de produtos que utilizam nanotecnologia, dentre eles nanopartículas ou nanomateriais relacionados à saúde", sob Processo Interno de n. 25351.506163/2014 -74, e de relatoria do Diretor Fernando Mendes Garcia Neto ${ }^{3}$.

$\frac{{ }^{3} \text { Diário Oficial da União n. 242, segunda-feira, } 19 \text { de dezembro de 2016. Seção 1.p. } 87 .}{\text { CONPEDI LAW REVIEW | Braga - Portugal | v. } 3 \mid \text { n. } 2 \text { | p. } 480 \text { - } 502 \text { | JUL/DEZ. } 2017}$ 
Na contramão desse paradoxo tão importante deixado de lado pelo Brasil, a União Europeia (EU), a fim de dar continuidade em sua estratégia coordenada para 2020, reuniu, em consórcio, 35 parceiros de 12 países da EU para, juntos, desenvolverem pesquisas em um único projeto nomeado como Sustainable NanoInnovation $(\mathrm{SUN})^{4}$, com investimento total de 13.539.313 Euros; o maior da Comunidade Europeia.

Esse projeto que vem sendo desenvolvido desde a sua criação, $1^{\circ}$ de outubro de 2013 , diferentemente, dos demais espalhados ao redor da Comunidade, pretende, além de compreender as propriedades, interações, impactos e riscos dos nanomateriais, criar banco de dados e métodos; direcionar tais implicações para o setor industrial e, ao mesmo tempo, supervisionar os órgãos regulatórios. Trata-se de um processo de integração de baixo para cima com a geração de dados da nanoinovação voltada para o meio ambiente, saúde e segurança e de cima para baixo ao coordenar as ações de design em nanoescala de produtos e processos no setor industrial e regulatório, tudo de forma integrada e descentralizada. Isso ficou reportado no artigo intitulado SUN: Paving Sustainable Nanoinnovation, apresentado no World Sustainability Forum 2014.

A conclusão inicial a que chega o trabalho é de que o impacto desse projeto é configurar condições viáveis para as indústrias que inovam com nanotecnologias e aparelhar agentes reguladores com dados e ferramentas para abordar os desafios; apresentar respostas às autoridades regulatórias e abrir novas oportunidades para projetar inovações sustentáveis. Para isso, serão desenvolvidos métodos e ferramentas que predigam a exposição e os efeitos nocivos aos ecossistemas e aos humanos e a implementação de práticas preventivas para gestão dos riscos e do completo ciclo de vida de um nanomaterial.

Nessa corrida desenvolvimentista, indicadores de janeiro de 2017, publicados pelo Instituto StatNano: Nano Science, Technology and Industry Scoreboard ${ }^{5}$ aponta os Estados Unidos em primeiro lugar, no placar geral da produção científica em nanotecnologias em artigos publicados; também mostram os demais países que despontaram em publicações indexadas pela Web of Sciense: China em primeiro lugar, com 47.455 artigos publicados e em décimo lugar, a Espanha, com 3.056 artigos publicados. O Brasil ocupa a $17^{\mathrm{a}}$ posição mundial

\footnotetext{
${ }^{4}$ SUN significa Sustainable Nanoinnovation, ou seja, nanoinovação sustentável que envolve meio ambiente, saúde e segurança (EHS -Environmental, Health, Safety).

${ }^{5} \mathrm{O}$ principal objetivo do StatNano é monitorar continuamente as atividades dos países em termos de elaborar indicadores de nanociência, tecnologia e inovação, de caráter global e regional, bem como, as políticas de desenvolvimento em nanociência e nanotecnologia. O jornal informativo tem sido preparado para informar ao público, sempre, os últimos indicadores. Disponível em www.statnano.com. Acesso 15 Mai 2017. Tradução livre.
} 
com 2.471 publicações, na frente da Argentina, em 40a posição com 527 publicações e Chile, em 44 a posição com 347 publicações e demais países da América Latina. (STATNANO, 2017)

Também, segundo o StatNano (2017), nesse mesmo levantamento de janeiro de 2017, um total de 19.563 inovações nanotecnológicas foram patenteadas no escritório de marcas e patentes United States Protocol Trademark Office (USPTO), em 2016. Desse número, 50\% pertencentes aos Estados Unidos (4.316) e os demais divididos entre Coreia do Sul (914), Japão (819) e Taiwan (514). Já no escritório de marcas e patentes European Protocol Office (EPO), foram 3.589, distribuídas entre Estados Unidos em primeiro lugar, com 577; Alemanha com 289; França com 208; Japão com 188; Coreia do Sul com 105; Reino Unido com 81; Suíça com 75; Países Baixos com 71; China com 59 e Itália, em décima posição, com 49. O Brasil, em $32^{\circ}$ posição, com o registro de 3 patentes; Argentina com 1; e, Chile, com 1, também.

No Brasil, em particular, a situação científica é bem módica, mas, avança no cenário global. O país está inserido nessa corrida e lidera a produção científica na América Latina, ocupando a $1^{\circ}$ posição. É parte integrante do Mercado Comum do Sul (MERCOSUL) que representa $3 \%$ da pesquisa mundial. Vem, desde 2000, implantando políticas inclusivas e desenvolvimentistas em Nanociência e Nanotecnologia $(\mathrm{N} \& \mathrm{~N})$, consolidando a estratégia com a Lei de Inovação de 2016.

O StatNano produziu o relatório Nanotechnology in Latin America, com dados estatísticos a respeito da produção de artigos em N\&N de 2010 a 2015, confirmando que o Brasil lidera a América do Sul e que as investigações científicas na área avolumaram consideravelmente nesses últimos cinco anos.

Tabela 2: Ranking de publicações de artigos científicos em Nanotecnologia na América Latina

\begin{tabular}{lrrrr|r|r|r}
\hline Países & 2010 & 2011 & 2012 & 2013 & 2014 & 2015 \\
\hline BRASIL & 1221 & 1332 & 1552 & 1844 & 2114 & 2213 \\
MEXICO & 528 & 743 & 828 & 959 & 1073 & 1254 \\
ARGENTINA & 408 & 368 & 422 & 453 & 500 & 551 \\
CHILE & 149 & 165 & 221 & 238 & 282 & 299 \\
COLÔMBIA & 132 & 124 & 169 & 139 & 181 & 202 \\
VENEZUELA & 43 & 41 & 54 & 47 & 31 & 59 \\
EQUADOR & 3 & 4 & 10 & 6 & 38 & 46 \\
CUBA & 24 & 43 & 49 & 48 & 45 & 47 \\
\hline
\end{tabular}




\begin{tabular}{lrrrrrr} 
URUGUAI & 15 & 32 & 29 & 32 & 32 & 43 \\
PERU & 14 & 7 & 5 & 12 & 20 & 24 \\
COSTA RICA & 2 & 5 & 6 & 9 & 13 & 13 \\
BOLIVIA & 0 & 3 & 2 & 3 & 4 & 9 \\
PARAGUAI & 0 & 1 & 0 & 0 & 0 & 0 \\
\hline
\end{tabular}

Fonte: STATNANO, 2017.

Mais recentemente, o Instituto Brasileiro de Geografia e Estatísticas (IBGE) divulgou em 2016 o relatório PINTEC de 2014. O documento levantou dados que mostram que empresas de bens e serviços, tem inserido nanotecnologia em processos e produtos, afirmando no documento que "a biotecnologia e a nanotecnologia vêm cada vez mais se afirmando como tecnologias de propósito geral que, de tempos em tempos, surgem com o potencial de se espalhar e afetar diversos setores da economia.” (2016, p. 71)

O relatório mostra que $1,8 \%$ das empresas inovadoras inseriram nanotecnologia em sua atividade representando 975 empresas de um total de 2583 entrevistadas, registrando uma queda de 13,8\% em relação ao período anterior de 2011, sendo que dessas 975 empresas, 89,5\% inovaram com nanotecnologias; por sua vez, número superior ao período anterior.

Com relação ao modo de uso das nanotecnologias pelas empresas inovadoras, o relatório informou que identificou quatro categorias: usuário final $(60,6 \%)$; usuário integrador $(25,7 \%)$; produtor de insumos ou produtos ou processos nanotecnológicos (15,3\%); planejamento e desenvolvimento, insumos ou processos nanotecnológicos (18,3\%). A apropriação das nanotecnologias ficou concentrada no setor industrial, para seu uso produtivo, confirmando a tendência já apresentada na pesquisa de 2011 e confirmada na de 2014, com aumento expressivo.

Esse documento ressaltou ser o mercado deveras promissor e muitas empresas têm interesse econômico em inserir a nanotecnologia em sua atividade lucrativa por causa da economia nos custos da produção; em 2014, o patamar de investimentos remontou a US\$ 2,6 trilhões, ou seja, $15 \%$ da produção global de bens manufaturados.

O Laboratório Químico do Estado Sólido (LQES) divulgou em seu jornal de novidades de junho de 2016, que a Universidade do Estado de São Paulo (USP) e a Universidade de Campinas (UNICAMP) estão entre as instituições científicas mais produtivas na pesquisa em cosméticos no mundo, ocupando a $1^{\circ}$ e $8^{\circ}$ posições, conforme relatou o estudo do State of Innovation 2016, realizado pela área de negócios de propriedade intelectual e 
ciência da Thomson Reuters (2016). A área dos cosméticos é a que sofre maior intervenção do desenvolvimento proporcionado pelas nanotecnologias. Portanto, o mercado das nanotecnologias, no Brasil, é o do consumo.

O problema é que a busca pelo desenvolvimento ainda está concentrada na iniciativa privada sob a razão da política econômica de exploração linear. Os resultados econômicos otimizados pelas nanotecnologias indicam que há maior preocupação em concentração de riquezas do que valorização dos ecossistemas social e natural; sobretudo, os riscos não têm sido sopesados nas decisões empresariais, diante da falta de algum parâmetro científico que remonte aos malefícios quanto às interações moleculares e atômicas com as células humanas e naturais.

Recentemente, o Instituto de Pesquisas Econômicas Avançadas (IPEA, 2015) a fim de cumprir seus objetivos estratégicos para o Brasil elaborou o estudo "Megatendências Mundiais 2030: o que entidades e personalidades internacionais pensam sobre o futuro do mundo? Informa o documento que investimentos em ciência e tecnologia estão no topo das tendências, contendo quatro aspectos mundiais, dentre eles, o crescimento dos investimentos e aplicações no campo das nano e biotecnologias ${ }^{6}$.

E mais: a) manutenção da revolução tecnológica, integrando a biotecnologia, a nanotecnologia, as tecnologias da informação (TIC) e as tecnologias dos materiais em ritmo acelerado; b) manutenção dos avanços e aplicações tecnológicas no campo da engenharia dos materiais, principalmente nos setores eletrônicos, construção de aeronaves, automóveis e construção civil; c) Os biomateriais de alta funcionalidade serão desenvolvidos e estarão no mercado até 2030; d) manutenção dos avanços e aplicações no campo da nanotecnologia com propriedades melhoradas dos materiais, principalmente para usos em dispositivos computacionais de saúde, para monitoramento humano, liberação controlada de fármacos e próteses robóticas; revestimento e embalagens e monitoramento do meio ambiente; e) desenvolvimento de embalagem inteligente para alimentos e bebidas com base em nanotecnologia, até 2030. (IPEA, 2015, p. 117)

Engelmann $(2012 ; 2015)$ não está convicto de que o Sistema do Direito serve para acolher esses fenômenos de grande complexidade e, por isso, entende que a gestão

\footnotetext{
${ }^{6}$ Dispõe o documento que: "Nos estudos analisados, foram identificadas quatro megatendências, listadas a seguir, e 21 sementes de futuro relacionadas a essas megatendências, conforme será abordado ao longo deste capítulo. As megatendências são: • aceleração do desenvolvimento tecnológico, multidisciplinar, com aplicações tecnológicas cada vez mais integradas; • as TIC continuarão modificando a natureza do trabalho, a estrutura de produção, de educação, de relação entre as pessoas e lazer; • crescimento dos investimentos em automação e robótica; • crescimento dos investimentos e aplicação no campo da nanotecnologia e biotecnologia." (IPEA, 2017, p. 101)
} 
nanotecnológica está vinculada aos Organismos Internacionais e às grandes corporações e empresas. Portanto, a depender da tomada de decisão em desenvolvimento tecnológico e inovação dentro de um sistema econômico linear de exploração lucrativa que não leva em conta o Homem, mas, suas necessidades, utilidades e bem-estar medido pelo padrão comportamental de consumo, os riscos são emergentes.

Caubet explica que esse é o comportamento assumido pós- 1980, em especial, pelas sociedades de modernidade tardia, como no caso do Brasil, a que intitulou de irresponsabilidade organizada, caracterizada pela negligência, pelo desprezo pelo risco, descumprimento de regulamentos, legislações nacionais e internacionais pelos promotores do desenvolvimento com a conivência do Poder Público, no afã de conseguir mais poder, riquezas e alimentar as vaidades (2013, p. 20), característica dessas sociedades.

Beck assenta que uma das consequências disso é a mercantilização dos riscos que é capaz de alçar o sistema capitalista a voos maiores, um novo estágio de avanço, tal como previsto por Arendt e Luxemburgo (sic). A esse respeito cita Luhmann, para quem o sistema econômico tornou-se autorreferencial, ou seja, independente do ambiente de satisfação das necessidades humanas. (2011, p. 28)

Ao tratar de "O Tempo do Direito", Ost (1999) compreende três fases históricas para o risco assumido pelas sociedades. Para ele, as sociedades estão inseridas na terceira fase, qual seja, a do risco enorme, relacionado com as possíveis catástrofes, de efeitos irreversíveis e com pouco domínio sobre elas, conduzindo todos ao perigo sanitário, alimentar, tecnológico etc., ao que chamou "risco de desenvolvimento".

Lenoir (2003) menciona que Deleuze já havia premeditado as formas de controle social do presente início de século, a partir dos computadores e de um novo formato do capitalismo, não mais baseado em produção, mas, sobretudo, no consumo e na prestação de serviços, cujo objetivo é a dominação massiva.

Parece bem plausível nesta pista as ponderações de Arendt e Lenoir ao considerarem a possibilidade de todo esse desenvolvimento tecnológico servir para efetivar, definitivamente, as sociedades de controle.

A prova dessa perspectiva de controle é possível mediante os estudos neurocientíficos, os quais vêm aprimorando as intervenções nanotecnológicas no cérebro em nome de medidas terapêuticas, reabilitadoras e novos dispositivos para leitura cerebral e controle da mente, a fim de aumentar a capacidade mental humana. Tais avanços retratam a manipulação de 
controle social, mediante a implementação não cirúrgica dessas neurotecnologias através da computação ubíqua, das mídias sociais e do marketing. (LENOIR, 2003).

Lenoir cita Weiser e Seely, ambos da Xerox PARC: há mais de duas décadas, "visionaram uma infraestrutura de computação ubíqua: a saber, um mundo em que a computação desapareceria do computador de mesa e se fundiria com os objetos e superfícies do nosso ambiente" (2003, p. 15). Essa realidade já é experimentada, atualmente, pela Microsoft, em jogos eletrônicos que dispensam controlador manual para movimentar o jogo mediante o reconhecimento de gestos como interface e o sistema controlador cerebral por fone de ouvido, fundindo o virtual e o real. É o caso do aparelho eletrônico XBOX.

As preocupações do autor são relatadas com mais intensidade ao mencionar que a computação ubíqua pode interferir nos afetos porque tem o poder da manipulação psicológica do inconsciente comportamental e afetivo sem que seja percebida através das mídias sociais e uso dos smartphones, inclusive, isso vem sendo tratado por uma nova área científica: a neuroeconomia, que reúne a neurociência e o neuromarketing, capazes juntas, de manipular o inconsciente coletivo e definir escolhas premeditadas. (LENOIR, 2003, p.18)

Observa-se que todos os riscos apresentados, até aqui, a bem da verdade, não se podem dizer assumidos pelas sociedades, posto que, não são chamadas a opinar, discutir ou, sequer, instruídas a escolher e decidir a esse respeito, muito embora, se promova todo esse desenvolvimento em seu nome e para seu bem-estar; mas, sim, constituem claro aumento do abismo social entre ricos e pobres; entre países hegemônicos e hospedeiros escravizados; estimulam a corrida darwiniana pela sobrevivência do mais forte sobre o mais fraco, numa franca promoção da seleção natural da minoria que detém o conhecimento e controle informacional sobre a minoria massiva desinformada, ignorante e seduzida pelo fetiche do consumo programado no inconsciente coletivo, infantilizando o comportamento social e político das sociedades exploradas.

Maus (2000), ao analisar o comportamento de sociedades diluídas pelo individualismo exacerbado e a falta de organização social e política, como é o caso do Brasil, pilares da exploração econômica, da massificação do consumo, sobretudo, da perda de identidade cultural e da noção do imaginário coletivo, dispõe que esse é o perfil das sociedades infantilizadas.

Fica claro, até aqui, que o caos e a crise enfrentados pelo ser humano na idade da técnica são possíveis porque a técnica e o seu desenvolvimento são utilizados como ferramenta de dominação capitalista e de subjugação das massas. A técnica instrumental 
aliada ao capital tem sido o casamento perfeito, do qual o homem e o planeta foram divorciados, prestando-se ao papel de meros objetos de experimentos; objeto do próprio objeto.

Beck (2011) diz que não houve um divórcio, mas uma relação promíscua, pois, as ciências abandonaram a lógica experimental e associaram-se a economia, a política e a ética, convivendo em um concubinato não declarado.

Diante desse contexto aparentemente crônico e com nenhuma chance de reversão, que o diálogo entre Buber e Ost pode contribuir na (re) construção de paradigmas que sirvam de reflexão e (re) condução do homem como fim de todo desenvolvimento, e seja possível restabelecer a posição correta dos agentes na relação sujeito-objeto e, quiçá, alcançar alguma ponderação na decisão de aplicação e desenvolvimento da técnica que a torne saudável, boa, justa e igualitária, quiçá, até 2030.

\section{A retomada necessária da relação transcendental entre Eu-Tu como ferramenta de guinada na história mundial entre Eu-Isso e o Outro. A contribuição do diálogo entre Buber e Ost}

A relação entre o homem e a natureza é o cerne de todo o trajeto do Homem sobre a Terra. Foi da observação da natureza, do maravilhar-se com ela, que o Homem enxergou a si mesmo e, a partir dela passou a investigá-la, abstraí-la, elaborá-la, projetá-la e copiá-la, mediante a abstração e a criação da técnica até, tornar-se independente dela. A técnica não é nada além do que a capacidade humana neurosensorial que evoluiu a partir desse processo de observação da natureza e continua evoluindo, diferentemente, das outras espécies animais. (PINTO, 2005, p. 30)

A história mostra que ao Homem foi concedida essa capacidade evolutiva neurosensorial, a tal ponto de, nesse momento da humanidade, não mais associar-se à natureza, mas, sim, subjugá-la.

Giacoia Junior (2004), em "sobre ética e humanismo" comenta que o homem se perdeu na razão instrumental, separando-se das motivações intelectuais estabelecidas na era do Esclarecimento. Para ele é visível que a técnica suplantou os apontamentos de Bacon, Descartes e Kant, pois no que concerne à natureza humana objetivada na perspectiva tecnocientífica, significa dizer que tal está disponível para a sua operacionalização como meio em vista de fins, característica da racionalidade instrumental. Diz que violados são valores 
universais humanistas, como autonomia e dignidade. Sobretudo, o excesso de autodeterminação despreza os valores éticos.

Os gregos entendiam que o homem era parte integrante do cosmo e por isso, capaz de racionalizar a partir dele, assumindo sua posição ínfima de um todo que jamais poderia dominar, sem se autodestruir.

Ésquilo (525 - $456 \mathrm{aC})$ explicou, através da mitologia de Prometeu Acorrentado, que o deus Prometeu, desobedecendo o império de Júpiter e, por amor aos homens, para tirá-los da estupidez, os ensinou muitas ciências e arte. E foi através do fogo celeste concedido, que os homens não desejaram mais a morte e passaram a ter esperança no futuro. Por essa conduta de desobediência, Prometeu foi condenado por Júpiter a ficar acorrentado eternamente. Júpiter alegou que o homem estaria vulnerável nessa condição do conhecimento dos deuses, pois, o excesso da razão técnica o escravizaria, a tal ponto de não mais conseguir pensar ou existir sem dela. Dentre os argumentos de Prometeu aos seus interpeladores, que se condoeram com sua condenação diante dos benefícios trazidos a humanidade, explicou que o homem vivia em desespero, como formigas em cave escura na terra e, então, os acudiu, ensinando números, alfabetos, memorização, artes industriais, distinção das estações da natureza e, sobretudo, a subjugá-la. Trouxe inventividade e engenhosidade para a vida humana na terra.

De lá para cá, as previsões filosóficas gregas se confirmaram.

No dizer de Supiot (2007, p. XIII), o homem racional repousa na técnica estrita do capitalismo que, por sua vez, trabalha com a ideologia inerente ao sistema, "na crença de que o ser racional é um puro ser de cálculo e que seu próprio comportamento, pode, portanto, ser calculado e programado"; sobretudo, que o campo do conhecimento humano está invertido. O homem projeta a técnica e usa a técnica para (re) projetá-lo, como uma máquina de calcular e, assim, espera "com a ajuda das nanotecnologias, alcançar o domínio material do pensamento”. (SUPIOT, 2007, XII)

Dessas afirmações é possível notar que o estado de escravidão do homem pela técnica está consumado, pretende, de per si, ser orientado e capacitado por ela. As nanotecnologias são hábeis para esse tipo de intervenção do homem no próprio homem, distanciando-o, cada vez mais, de sua natureza transcendental e, consequentemente do Outro social.

Interessante notar que Supiot também se socorre dos argumentos, ao lado de outros tantos, que marcam esse comportamento entre a ciência e a técnica no homem, a partir do fato judaico-cristão de Deus dar a Terra como herança aos homens para sua dominação, sendo essa a identidade adotada pelos povos do Ocidente (2007, p. XV), quando, desde antes do 
nascimento, vida e morte de Jesus, a exemplo do texto grego de Ésquilo, a subjugação da natureza já era fato humano, inclusive, dada a conhecer por outro deus, que não, o Deus da criação, judaico-cristã. Esse relato grego que antecede não pode ser ignorado.

A análise desse cenário por Buber (2001) é pontual na tratativa dessa relação rompida entre $\mathrm{Eu}$ - o homem, e Tu - o Ser transcendental que tudo criou. As consequências são nefastas à existência na terra porque amasiou-se, de forma excessiva e perversa com Isso, que o domina e o escraviza, a ponto de não viver sem ela, e morrer e matar por ela. Além do mais, com o afastamento de $\mathrm{Tu}$, Eu se afastou do Outro que, no início, era sua própria expressão. Aqui reside o novel aspecto deste ensaio.

O dilema da ruptura transcendental de Buber vai de encontro à razão pela qual isso ocorreu: a paixão excessiva e promíscua pela técnica em todo o pensamento humano e o desprezo, o desapego do Outro.

Daí ser possível apresentar como hipótese, o reatar entre $\mathrm{Eu}$ e Tu, colocando Isso no seu devido lugar: o de servir ao homem na exata medida de suas necessidades que compreendem o nascimento, a vida e a morte, em todo seu caráter individual e ou coletivo, diante do Outro, convencendo-o de que é o melhor a fazer para a humanidade: retornar ao seu Criador e estabelecer a razão humana a partir da sua transcendentalidade. Assim, o Eu sempre será adequadamente projetado no Outro e vice-versa.

Buber trata essa transcendentalidade perdida como a palavra-princípio que rege a estrutura existencial e essencial do homem, enquanto estiver sobre a terra; é a pedra fundamental onde repousa o diálogo ontológico; reflexivo e interior com o Tu; diálogo esse que informa ao Eu as bases de si-mesmo e a do Outro; onde mantem sua condição de parte integrante do sistema cósmico, transcendental; local onde reside o logos - a boa razão, que o aproxima de Tu, de Seus atributos, absorvendo-os de forma indentitária.

Por sua vez, Eu - Isso é a palavra-princípio que determina o diálogo do Eu com a experiência, o conhecimento e a técnica, sobretudo, coloca Eu em contato natural com o Outro, semelhante a si. Trata-se, assim, da práxis.

A figura central desses diálogos é o Eu. É a partir da integralidade do seu ser que as palavras-princípio acontecem e os resultados são exteriorizados em face do Outro: ou pela aproximação com Tu e suas virtudes; ou pela aproximação com Isso e suas virtudes ou desatinos. Todavia, seja qual for a escolha exercida por Eu, os resultados serão projetados no Outro, seu semelhante: ou todos se enxergam como fins ou todos se enxergam como meios. 
Em ambos os diálogos é o homem que abre a palavra-princípio que escolhe pelo livre arbítrio, e para cada diálogo, usa do idioma adequado, pois, seus interlocutores falam línguas diferentes. Eu é a ponte de intersecção, o ponto convergente da triangulação, ora pelo logos ora pela práxis.

Todavia, Tu é primordial para Eu, pois lhe confere existência ontológica, sendo Eu criação e parte de Tu. Isso, vem em um segundo momento; uma segunda relação objetiva, útil, experiente, cognoscitiva com Eu. Von Zuben, no prefácio à obra de Buber elucidou muito bem a distinção: "as duas palavras-princípio instauram dois modos de existência: a relação ontológica Eu-Tu e a experiência objetivante Eu-Isso”. (BUBER, 2001, p. 32)

A prevalência de uma relação sobre outra reside no fato da totalidade da inter-relação. Se a relação entre Eu-Tu se der na totalidade do seu ser, certamente, todos os atributos de Tu estarão manifestos em Eu e, portanto, no Outro; ao contrário, também, é verdade: se Eu se relacionar na sua totalidade com Isso, a sua essência deixa de ser transcendental e ontológica para ser experiência pura, conhecimento, técnica e utilização; gozo e fruição egoística, impessoal.

Daí clara a compreensão de que na relação Eu-Tu, ambos se inter-relacionam enquanto pessoas; na relação Eu-Isso, o Eu é o sujeito da experiência, do conhecimento, do uso, da técnica, do desenvolvimento e, portanto, dialoga consigo mesmo, sendo Isso, o objeto. Ambos relacionamentos traduzem para Eu diferentes tipos de apreensão da realidade e na construção de significados; de sentidos.

Quando Eu tem um encontro com Tu, o caráter da relação é ontológico e parte da contemplação e da doação entre ambos, donde Tu se revela para Eu, que aceita Tu como referência de vida; já, quando Eu tem um encontro com Isso, gera conhecimento, experiência, inteligência, apreensão do ser como objeto, auxiliando $\mathrm{Eu}$ a tornar-se um ser presente. $\mathrm{O}$ universo do Isso é coerente e ordenado, indispensável para a existência humana, mas, nada tem de ontológico na relação.

A história da evolução humana mostra que Eu divorciou-se de Tu, pois, apaixonou-se por Isso e com ele passou a inter-relacionar-se, integralmente, esquecendo-se de suas raízes ontológicas e transcendentais, transformando seu ser em um com Isso, lugar em que não cabe o Outro.

A ferramenta da sedução foi a técnica, que proporciona a $\mathrm{Eu}$ todos os meios necessários para sobreviver na terra, sem depender de qualquer relacionamento com $\mathrm{Tu}$, inclusive, dispensando-o da redenção que o atormenta. Eu descobriu que poderia ser criador 
como $\mathrm{Tu}$, consolidando, de uma vez por todas, o rompimento transcendental, passou a subjugar para si, com poder, todo o bem do qual era parte integrante, tal como relatado em $\mathrm{O}$ mito de Prometeu.

Buber (2001) diagnosticou esse divórcio e alertou para as consequências preocupantes que adviriam desse distanciamento entre $\mathrm{Eu}-\mathrm{Tu}$, já que o rompimento representava para Eu a perda de si-mesmo e da noção transcendental do Outro. Uma vez perdido tal interrelacionamento toda a humanidade seria afetada.

Arendt, como a frente do seu tempo, também vislumbrou o caos promovido pela perda do logos e a supervalorização da práxis como sendo um processo destrutivo das tradições e da própria existência humana, o que levaria o homem à "perda de sua profundidade, sem a qual não pode existir o pensamento humano, mesmo no mero nível de invenção técnica”. (2008, p. 96)

Com essa compreensão buberiana, que data de 1923, é possível constatar que sua análise filosófica sobre a perda da capacidade ontológica do homem e a projeção do caos em decorrência disso estava correta. Os efeitos crescentes desse rompimento são sentidos, fortemente, nesse primeiro quarto de século e se estenderão nas megatendências para 2030, em se tratando do desenvolvimento e exploração econômica das nanotecnologias em âmbito global, especialmente, nos casos das sociedades de modernidade tardia ( $\mathrm{sic}$ ), como no caso do Brasil.

A supervalorização da técnica promoveu o endeusamento de Isso e a escravidão sacrificial de Eu e, como consequência, do Outro (o semelhante; o planeta). A ontologia do homem, de transcendental passou a ser a própria técnica e como consequência a do capital, sendo esse o ponto de contato e de expressão entre Eu e o Outro: o avanço tecnológico e o proveito econômico para subjugação e exploração, sendo essa o estado das artes da filosofia da técnica: a Era do Homem.

Buber (2001) avança para anotar que o problema do homem não reside na ética, ou na ausência dela, mas, sim, na ausência da ontologia reflexiva, existencial, cujo distanciamento de Tu, tem eivado a sociedade a bancarrota. Ao divorciar-se de Tu, Eu também se distancia de si-mesmo e, como consequência, do Outro; e, por isso, a sociedade enfrenta sua decadência em queda-livre, de forma egoística, impessoal e panótica.

Se para Buber a transcendentalidade é a resposta para Eu retomar a concepção humana de si-mesmo e do Outro, como parte integrante de um todo cósmico e harmônico, para Ost, a 
resposta para Eu é o melhor aproveitamento do imaginário social, pois é capaz de conduzir o homem ao logos adequado que o coloca diretamente em frente a práxis técnica. Tanto Buber quanto Ost passam pela compreensão de que Eu deve se divorciar de Isso, quer pela autorreflexão, quer pelas verdades históricas que emergem desse imaginário social, instituinte e civilizatório, sobretudo, de caráter humano. (OST, 2004)

Uma das áreas de afetação pelo excesso da razão instrumental contemporânea é a destruição das tradições familiares e sociais; laços de afetividade coletiva, por isso, hoje em dia, os cientistas das humanidades ressaltam a necessidade do retorno aos sentimentos. Há uma tentativa agressiva de remodelagem dos padrões sociais e culturais; as tradições culturais e os pensamentos filosóficos passam por reestruturação involuntária e estrategicamente projetada pela globalização econômica que busca a massificação e a padronização comportamental para viabilizar a dominação.

Nesse sentido, o trabalho de Ost em Contar a Lei é assaz atroz em alertar a sociedade para essa destruição massiva dos pilares fundamentais dos vínculos sociais de uns para com os outros e que a individualidade é o meio para se manejar o fim das tradições, pedra angular da unidade social. (2004, p. 13)

Daí considerar a dialética entre Buber e Ost cooperativa para confirmar a hipótese de que falta ao homem a razão transcendental e o próprio aparato social organizado no inconsciente e consciente coletivos que, registrados nos arquivos da história ao longo dos tempos, pode contribuir com a retomada do logos.

Enquanto a transcendentalidade reforça o ser em si-mesmo, o imaginário social reflete no corpo social, o Outro, como um círculo virtuoso: Eu se encontra com o Tu transcendental refletindo-se no Outro que, por sua vez, responde positiva e construtivamente para Eu, e ambos constituem o ideal social como protagonista do cenário político, econômico, cultural e emancipatório: ninguém corta a própria carne em perfeita razão transcendental de si-mesmo!

A partir desse cenário social, instituídos são os poderes, retomando o logos e reposicionando a práxis, para quem a ciência e a técnica não podem ditar as regras do jogo cênico, pois, são dela objeto.

O imaginário social, para Ost, é o retrato completo e verdadeiro da vida das pessoas em sociedade, pois, se projetam em um único cenário, um único texto, uma única peça, um único roteiro, questões sociais de magnitude ampla, sem recortes epistemológicos; se prestam a observação de qualquer área, inclusive, no domínio da ética, em que o sistema não pode corromper ou intervir, mas dela podem sair valores que serão multiplicados no aparato 
comunitário. É o que ele chama de "função de rememoração", que mantem a forma instituída e por isso, "fornece então o melhor dela mesma: produz efeitos instituintes de mobilização de significações novas" (2004, p. 23)

Se essa análise de Ost se confirmou até ontem, há de se esperar que seja reforçada no futuro, diante das megatendências mundiais para 2030, já que o estudo do Instituto de Pesquisas Econômicas Aplicadas informa, pelos dados, que a classe média vai aumentar exponencialmente e, por isso, haverá maior empoderamento dos indivíduos e da sociedade civil organizada acerca das questões sociais (organizações não governamentais; redes civis nacionais e transnacionais; empresas privadas), de consumo e figurará como produtor-chave das tecnologias. Tal expectativa se dá por causa da melhoria do ensino no mundo e a forma do acesso digital (até 2030, 90\% da população mundial estará alfabetizada).

Salienta que esse empoderamento atingirá melhores padrões de governança e ação cívica; gerará poder paraestatal que colocará em questão as instituições públicas e seus poderes, participação direta na política; exigências por melhores condições de vida. Assim, entremeios ao cenário de insegurança presente, há alguma perspectiva de reorganização social se esse eficaz imaginário social for retroalimentado com valores transcendentais de ética, moralidade, de reto conselho; com alguma relação entre Eu-Tu-Outro, dentro do seio social.

Weber (2004) explicou que o espírito do capitalismo, cuja marca é a "individualidade histórica", é caracterizado pela filosofia da avareza não sinônima de uma boa perspicácia nos negócios, mas, sim, por um comportamento de valor ético norte americano e da Europa Ocidental que entendem razoável maximizar lucros enquanto for possível - regras do utilitarismo; da utilidade da ética, das virtudes; do dinheiro como fim em si mesmo.

Galimberti, usando outro discurso, assenta que se o dinheiro se torna "o fim último, todos os bens que não são de natureza econômica, como a inteligência, a cultura, a arte, a força, a beleza, o amor, deixam de ser valores em si”. (2004, p. 50). As megatendências do IPEA (2017) provam os assentamentos de ambos os autores.

Em se tratando de nanotecnologias, há necessidade de se trabalhar o imaginário social. É ele quem assume a "função de conversão fundadora" (Ost, 2004, p. 26), já que pouquíssimas pessoas, além do âmbito acadêmico das ciências naturais, sabem tratar das implicações nanotecnológicas. A narrativa se faz imprescindível para instituir esse momento diante do fenômeno. 
Deve sim, ser desmistificada a ideologia falsa de que os avanços nanotecnológicos são a panaceia do presente, com vistas ao futuro, enquanto as certezas científicas não forem, ao menos, conhecidas e retirar desse discurso, o valor moral que lhe é atribuído e que promove a crise sistêmica. A técnica não deve e não tem valor moral para a sociedade. A técnica é desenvolvimento; é funcional; não está a serviço da moral e da ética, que pertencem a subjetividade humana que deve ser preservada para refletir a sociedade que se constrói no presente com vistas à estruturação das gerações futuras, através do imaginário social conformador para o futuro.

\section{Conclusão}

É fato que a supervalorização da técnica conduziu o Homem ao esmagamento daquele que não a possui, pois, seu domínio representa concentração de riquezas e poder de mando, desde o menor núcleo social até magnitudes globais.

As elementares para a alavancagem da razão estão muito bem definidas: dinheiro, poder e tecnologias. Com isso, a razão técnica alcançou seu ápice de irracionalidade: os riscos do desenvolvimento ao próprio homem e ao ecossistema, bem como, o aprimoramento da segregação entre os povos. A bem da verdade, nesse estágio, é possível um novo holocausto para a efetiva redução de massas; aquelas que não interessam ao sistema nefasto, que não detêm o poder de decisão sobre a razão técnica, ou dela não façam parte ou estão a ela submetidas. A nanotecnologia é a ferramenta da vez!

O problema foi enfrentado com dados econômicos do IPEA, do Ministério de Ciência e Tecnologia, da Associação Brasileira do Desenvolvimento Industrial e da Agência de Vigilância Sanitária, que demonstram pouca ou nenhuma mudança, presente ou futura, a respeito das implicações do momento diante das megatendências (2030) de desenvolvimento, acumulação de riquezas e tecnologias, mundiais. Inclusive, essa engrenagem funciona por estradas que violam a estrutura de desenvolvimento econômico do Brasil, orientada pelas diretrizes do artigo 170, da Constituição Federal de 1988.

A proposta para o enfrentamento do problema do excesso da razão instrumental e o esquecimento do Homem como fim do desenvolvimento, certamente deve passar pelo fortalecimento da filosofia do Homem como ser transcendental que é, pelo poder instituinte do imaginário social e a valorização das tradições históricas para o devido reposicionamento da práxis, confirmando a hipótese inicial. Ao menos, como forma de fortalecer a resistência e a resiliência à força motriz que vem consolidando o sistema dominado pela razão técnica. 
A hipótese, entretanto, pode extravasar o âmbito do pensamento da pesquisa e atingir, em cheio, a práxis.

O Centro de Gestão de Estudos Estratégicos ${ }^{7}$ (CGEE) vinculado ao Ministério da Ciência, Tecnologia e Inovação (MCTI), portanto, de interesse nacional e que tem por missão subsidiar processos de tomada de decisão em temas relacionados à ciência, tecnologia e inovação no país, por meio de estudos que orientem as estratégias e articulam todos os interesses que compõem o sistema nacional, deve ser a bola da vez, onde todas as jogadas do país sejam concentradas na atuação desse órgão institucional; atuação como líder.

Para melhor cumprimento dos objetivos desenvolvimentistas nacionais e reforçar a potencialidade da ação institucional é em boa hora que, diante das incertezas científicas quanto aos riscos nanotecnológicos pelos levantamentos das informações e a dificuldades de orientação política e para a tomada de decisão é necessário que o CGEE:

$1^{\circ}$. Centralize as informações produzidas em todo o território nacional; $2^{\circ}$. Determine, mediante normatização jurídica legítima, a transparência informacional para todos os envolvidos no desenvolvimento e pesquisas das nanotecnologias e, com isso, crie um banco de dados que seja alimentado por todos e tenha caráter público; $3^{\circ}$. Determine, oriente, mediante normatização jurídica legítima, que os investimentos em desenvolvimento e pesquisas sejam, no mínimo, iguais; $4^{\circ}$. Adote política de informação aos cidadãos a fim de promover maior eficiência na gestão dos riscos pela percepção pública formada pelo imaginário social instituinte; $5^{\circ}$. Adote políticas de envolvimento entre universidades, empresas, governo e sociedade civil organizada no planejamento estratégico nacional.

Como resultado, a formação de um ciclo virtuoso em torno do desenvolvimento das nanotecnologias e a gestão dos riscos. É do pensamento filosófico a percepção pública dos riscos e a conformação do imaginário social. Portanto, é possível contribuir com o desenvolvimento compartilhado para reposicionar o Homem como fim de todo o desenvolvimento.

\section{REFERÊNCIAS}

ARENDT, H. (2008). Homens em tempos sombrios. São Paulo: Companhia das Letras.

\footnotetext{
${ }^{7}$ Estatuto do CGEE atualizado em julho de 2012 e registrado em cartório em dezembro de 2012 - Resolução CA $\mathrm{n}^{\circ} \quad 129 \quad-\quad$ Disponível em $\quad$ http://www.cgee.org.br/arquivos/cgee_estatuto.pdf e http://www.cgee.org.br/sobre/finalidade.php. Acessados em 24 Mar 2017.
} 
BARDIN, L. (2011). Análise de conteúdo. (L. A. Reto, \& A. Pinheiro, Trads.) São Paulo: Edições 70.

BAUMANN, Z. (2015). A riqueza de poucos beneficia todos nós? (Aguiar R. Trad.) São Paulo: Zahar.

BECK, U. (2011). Sociedade de risco (2 ed.). São Paulo: Editora 34.

BRASIL. Agência Brasileira De Desenvolvimento Industrial. ABDI. Panorama nanotecnologia / Agência Brasileira de Desenvolvimento Industrial. - Brasília: ABDI, 2010. Disponível em http://www.abdi.com.br/Paginas/estudo_detalhe.aspx?e=Estudos\%20Setoriais\%20de \%20Inovacao\&f=Nanotecnologia\&n=1 Acesso 25 Mai. 2017.

BRASIL. Agência de Vigilância Sanitária. ANVISA. Diagnóstico Institucional de Nanotecnologia. Brasília, DF: ANVISA, 2014. Disponível em Disponível em http://portal.anvisa.gov.br/wps/wcm/connect/fb117d80436c3cacb1b5b72a042b41f5/ Diagn \%C3\%B3stico+Institucional+de+Nanotecnologia+-+CIN+2014++Dicol.pdf?MOD=AJPERES. Acesso 10 Mai 2017.

BRASIL. Instituo Brasileiro de Geografia e Estatística. IBGE (2016). Pesquisa de Inovação 2014. Rio de Janeiro: Embrapa, 2016. Disponível em http://www.pintec.ibge.gov.br/index.php?option=com_content\&view=article\&id=45 \&Itemid=12. Acesso 31 Abr. 2017.

BUBER, M. (2001). Eu e Tu. (N. A. Zuben, Trad.) São Paulo: Centauro.

CAUBET, C. G. (jan-jun de 2013). O conceito de sociedade de risco como autoabsolvição das sociedades industriais infensas à responsabilidade jurídica. Cadernos de Direito, Vol. 13(24).

CUPANI, A. (2014). A realidade complexa da tecnologia. (I. H. Unisinos, Ed.) Cadernos IHU Ideias, vol. 12.

ENGELMANN, W. (2007). Direito Natural, Ética e Hermenêutica. Porto Alegre: Livraria do Advogado.

ENGELMANN, W. (2012). O diálogo entre as fontes do Direito e a gestão do risco empresarial gerado pelas nanotecnologias: construindo as bases à juridicização do risco. Em L. L. STRECK, L. S. ROCHA, \& W. (ENGELMANN, Constituição, Sistemas e Hermenêutica: Anuário do Programa de Pós-Graduação em Direito (Vol. 9, pp. 319-344). Porto Alegre: Livraria do Advogado. 
ENGELMANN, W. (2015). Primeras tentativas de reglamentación de las nanotecnologías en Brasil. Em G. e. FOLADORI, \& M. Á. Porr (Ed.), Nanotecnologías en América Latina: trabajo y regulación (pp. 41-56). México: Universidad Autônoma de Zacatecas.

ENGELMANN, W; WILLIG, J. R. (2016). Inovação no Brasil: entre os riscos e o Marco Regulatório. Jundiaí: Paco Editorial.

ÉSQUILO. (s.d.). Prometeu Acorrentado. Acesso em 20 de mar de 2017, disponível em http://www.ebooksbrasil.org/eLibris/prometeu.html

GALIMBERTI, U. (2004). Os vícios capitais e os novos vícios. São Paulo: Paulus.

GALIMBERTI, U. (26 de outubro de 2014). A dimensão racional da técnica e a modelagem da vida. Entrevista especial com Umberto Galimberti. (U. d. Sinos, Ed.) Acesso em 11 de maio de 2017, disponível em Instituto Humanitas Unisinos: http://www.ihu.unisinos.br/entrevistas/536697-a-dimensao-racional-da-tecnica-e-amodelagem-da-vida-entrevista-especial-com-umberto-galimberti

GALIMBERTI, U. (2015). O ser humano na era da técnica. (I. H. Unisinos, Ed.) Cadernos IHU Ideias, 13(218).

GIACOIA JR., O. (2004). Sobre ética e humanismo. Caderno IHU Ideias, 2(20.). Acesso em 22 de Mai de 2017, disponível em www.ihu.unisinos.br

INSTITUTO DE PESQUISAS ECONÔMICAS AVANÇADAS. (14 de Out de 2015). IPEA. Megatendências Mundiais 2030: O que entidades e personalidades internacionais pensam sobre o futuro do mundo? Acesso em Mai de 15 de 2017, disponível em http://www.ipea.gov.br/portal/index.php?option=com_content\&view=article\&id=264 $50 \&$ catid $=345 \&$ Itemid $=38$

LENOIR, T. (2003). Neurofuturos para sociedades de controle. Caderno IHU Ideias, 1(1). Fonte: www.ihu.com.br

MAUS, I. (Nov de 2000). O judiciário como superego da sociedade. Novos Estudos, pp. 183202.

OST, F. (1999). O Tempo do Direito. Lisboa: Piaget.

OST, F. (2004). Contar a lei: as fontes do imaginário social. (P. Neves, Trad.) São Leopoldo: UNISINOS.

PINTO, Á. V. (2005). Conceito de Tecnologia (Vol. I). Rio de Janeiro: Contraponto. 
STATNANO. (2017). StatNano Index. (StatNano) Acesso em 15 de Mai de 2017, disponível em StatNano: http://statnano.com/

SUPIOT, A. (2007). Homo juridicus: ensaio sobre a função antropológica do Direito. São Paulo: Martins Fontes.

THOMSOM REUTERS. (2016). Disruptive, game-changing innovation. Acesso em 31 de Mai de 2017, disponível em 2016 State of Innovation:

http://images.info.science.thomsonreuters.biz/Web/ThomsonReutersScience/\%7B81d 76ae6-9d3b-453c-8f7c-b76a3c80046d\%7D_2016_State_of_Innovation_Report.pdf

WEBER, M. (2004). A ética protestante e o espírito do capitalismo. (J. M. Macedo, Trad.) São Paulo: Companhia das Letras. 